\title{
Influence of standard Korean and Gyeongsang regional dialect on the pronunciation of English vowels
}

\author{
Soo-Yeon Jang* \\ Department of English Language and Literature, Yonsei University, Seoul, Korea
}

\begin{abstract}
This study aims to enhance English pronunciation education for Korean students by examining the impact of standard Korean and Gyeongsang regional dialect on the articulation of English vowels. Data were obtained through the Korean-Spoken English Corpus (K-SEC). Seven Korean words and ten English mono-syllabic words were uttered by adult, male speakers of standard Korean and Gyeongsang regional dialect, in particular, speakers with little to no experience living abroad were selected. Formant frequencies of the recorded corpus data were measured using spectrograms, provided by the speech analysis program, Praat. The recorded data were analyzed using the articulatory graph for formants. The results show that in comparison with speakers using standard Korean, those using the Gyeongsang regional dialect articulated both Korean and English vowels in the back. Moreover, the contrast between standard Korean and Gyeongsang regional dialect in the pronunciation of Korean vowels $(/ \mathrm{O} /, /$ 어/) affected how the corresponding English vowels $(/ \mathrm{\partial} /, / \mathrm{J} /)$ were articulated. Regardless of the use of regional dialect, a general feature of vowel pronunciation among Korean people is that they show more narrow articulatory movements, compared with that of native English speakers. Korean people generally experience difficulties with discriminating tense and lax vowels, whereas native English speakers have clear distinctions in vowel articulation.
\end{abstract}

Keywords: formant frequencies, Koreans' English pronunciation, Korean vowels, regional dialect

\section{1. 서론}

본 연구의 목적은 서로 다른 두 지역 방언을 이용하는 화자들 이 영어 모음을 발음할 때 보이는 특징을 알아보는 데 있다. 외 국어 발음 오류 현상에 관한 연구는 지속되어 왔다. Park(2009) 는 한국인의 영어 발음 오류는 L1 화자가 L2 모음 체계를 습득 할 때 발생하는 모국어 음운체계의 간섭(interference) 현상 때문
이라고 설명하고 있다. 이와 관련하여 영어와 다른 한국어의 자 모음 체계가 영어 자모음 발음에 영향을 주는 한국어 간섭 현상 (Korean interference)에 관한 연구도 많이 선행되어 왔으며 (Hwang, 2001; Hwang \& Moon, 2005; Lee \& Cho, 2013; Lee et al., 2019; Park et al, 2010), 한국어 방언의 발음 특징이 영어 발음에 미치는 영향에 관한 연구도 여럿 존재한다(Koo, 2001; Myung \& Lee, 2014; Seo, 2011). Koo(2001)는 서울, 경상, 호남 지역 출신

* sooyun1300@naver.com, Corresponding author Received 3 August 2021; Revised 12 December 2021; Accepted 12 December 2021

(C) Copyright 2021 Korean Society of Speech Sciences. This is an Open-Access article distributed under the terms of the Creative Commons Attribution NonCommercial License (http://creativecommons.org/licenses/by-nc/4.0) which permits unrestricted non-commercial use, distribution, and reproduction in any medium, provided the original work is properly cited. 
의 피실험자를 선정하여 포먼트 주파수 분석을 통해 그들의 한 국어와 영어 모음 발음 특징을 비교하였다. 그 결과 서울 방언 화자는 중설 모음 발음이 후설쪽에서 발음되고 영남 화자는 후 설 모음을 발음하는 데 어려움이 있다는 점을 밝혔다. $\operatorname{Seo}(2011)$ 의 연구에서는 대구지역과 제주지역 화자의 한국어 모음 발음 의 영향으로 한국어 모음을 발음할 때 드러나는 각 지역 방언의 조음 특징을 영어 모음 발음시 대치시켜 조음한다는 점을 증명 하였다. Myung \& Lee(2014)는 같은 한국어 화자일지라도 지역 마다 화자들이 구사하는 방언의 차이가 존재하며, 지역 방언의 차이가 한국어 모음뿐만 아니라 영어 모음 발음 시에도 음향 공 간상의 영향을 미쳐 조음 차이가 발생한다고 밝혔다. 더불어, 한국어 모음을 발음할 때 경남 방언 화자가 표준어 화자보다 조 음 위치가 후설쪽으로 치우쳐져 있으며, 후설 고모음(/우/)을 발 음할 때 도드라지게 강한 후설성이 그에 대치되는 영어 모음 발 음에서도 차이를 보인다는 결론을 얻었다. 따라서 본 연구에서 는 서울 지역 화자와 경상도 지역 화자를 대상으로 한국어와 영 어 모음 발음 특징에 대한 분석이 진행되었으며, 서울과 경상도 방언 각각에서의 한국어 모음 특징이 영어 모음을 발음할 때 미 치는 영향을 관찰해볼 것이다. 더 나아가 한국어 모음 발음의 전반적인 특징으로 인해 발생한 영어 발음 간섭 현상과 지역 방 언의 특성에서 비롯된 영향으로 간주할 수 있는 현상을 더욱 명 확히 분리하여 분석하는 것을 목적으로 한다. 도출된 결과는 한 국어 화자들의 영어 발음 교육에 도움이 될 수 있으며, 한국인 의 영어 발음 교육 방식을 일반화시키는 대신 화자의 지역 방언 사용을 고려하여 이에 적합한 교육 방식을 제시하는 데 활용할 수 있을 것이다.

\section{2. 연구 방법}

영어 모음 발음에 영향을 미치는 한국어 지역 방언의 음향음 성학적인 요소에 대하여 알아보고 이를 올바른 영어 모음 발음 교육에 활용하기 위한 연구방법은 다음과 같다.

\section{1. 피실험자}

성별, 연령별, 지역별로 구분 지어진 K-SEC(Korean-Spoken English Corpus) 자료 중 피실험자는 성별, 나이, 최종학력, 음성 학 교육 이수 정도, 해외 거주 경험 등 생물학적 및 사회적 요소 가 유사한 발화자들의 음성 파일을 선별하여 분석을 진행하였 다. 본 연구의 분석에 사용된 자료의 발화자들은 모두 남성이며, 대학생이나 대학원생이다. 또한, 영어를 제 1 언어로 사용하는 국가에서 거주기간이 1 년 미만이다. 이와 같은 기준을 갖춘 서 울 지역화자 7명과 경상 지역화자 7명을 각각 선정하였다.

\section{2. 연구 자료}

본 연구에서는 한국인에 의해 발화되는 영어음의 디지털 녹 음 자료인 '한국인의 영어 발음 음성 코퍼스(K-SEC)'를 활용하 였다(Rhee et al., 2003). 해당 연구 자료는 독립어와 문장 및 이야 기 낭독체 발화로 구성되어 있으며, 다섯 세트(set 1-set 5)로 분
류된다. 한국어 독립어를 녹음한 set 1 에서 1 음절어 7 가지와 영어 독립어 어휘가 녹음된 set 4 에서 1 음절어 10 가지를 선정하였다.

실험자료 1:/이/,/애/, /으/,/어/,/아/,/우/, /오/

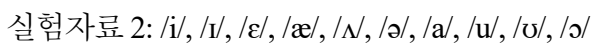

한국어와 영어 독립어 선정 기준은 각각 실험자료 1 과 실험 자료 2의 모음 발음 체계를 기준으로 삼았다. 한국민족문화대 백과사전의 표준 발음법에 따르면 한국어 단순 모음은 8 모음 체계를 허용하고 있지만, 현실 생활에서는/에/와/애/의 구분이 사라진 7 개의 발음을 한다. 또한, 경상도 지역에서는 /어/와 /으/ 의 구분이 없어진 6 개의 단모음만을 발음한다. 따라서 본 연구 에서는 실험자료 1 에 명시한 바와 같이 현실에서 주로 사용되 는 7 개의 한국어 모음 발음을 선정하였다. 더불어 실험자료 2 는 국제음성기호(international phonetic alphabet, IPA)에 따른 영어 의 10 단모음 체계를 기준으로 삼았다.

\subsection{1. 한국어 독립어 발성 자료}

Rhee et al.(2003)의 K-SEC 코퍼스 자료 구축에 관한 설명에 의하면 set 1 은 한국어 자모의 관찰과 영어와의 비교 및 대조를 위해 설계되었다. 초성에 올 수 있는 자음 18 개와 단모음 7 개를 조합하여 모아진 모든 어형을 2회씩 반복하여 총 98 개의 목록 을 작성하였다. 이는 실제어, 가상어, 이끔 문장(carrier phrase)를 포함한다. 98 개의 목록 중에서 본 연구 자료로 활용된 set 1 의 독 립어 목록은 아래와 같다.
[이]: 히다
[애] : 헤다
[으] : 흐다
[어] : 허다
[아] : 바다
[우] : 후다
[오] : 호다

\subsection{2. 영어 독립어 발성 자료}

Rhee et al.(2003)에서는 K-SEC 코퍼스 자료 중 set 4은 한국인 의 영어 독립어 발화에서 보이는 양상을 분석하고 원어민 발화 와의 차이점을 실험음성학적인 측면에서 관찰하기 위해 설정 되었다. 일반인용 어휘는 총 1,125 개를 수집하였고 각 어형은 한 번씩 발화되었다. 1,125 개의 목록 중에서 본 연구의 자료로 활용된 set 4의 독립어 목록은 아래와 같다.
[i] : keep, deer
[I] : dig, fit
$[\varepsilon]:$ desk, ken
$[æ]:$ map, cab
$[\Lambda]$ : hut, bus
[ə] : avoid, apart 
[a] : call, tall

$[\mathrm{u}]$ : proof, racoon

$[\mho]:$ pull, tool

[o] : talk, mall

2.3. 연구절차와 분석방법

$\mathrm{K}-\mathrm{SEC}$ 발화 자료들은 Window 11 환경에서 음성 분석 프로그 램 Praat 6.1.53을 통해 분석하였다. Praat의 스펙트로그램 (spectrogram)을 통해 모음의 음질을 측정하였다. 포먼트 플롯 기능(formant plot)을 사용하여 독립어 별로 일관된 측정지점을 기준 삼아 첫 번째 포먼트(F1)와 두 번째 포먼트(F2) 주파수를 측정하였다. Ladefoged \& Johnson(2011)에 따르면 스펙트로그 램에서 표시되는 모음의 포먼트는 5개인데 F1 주파수에서 모음 의 에너지를 가장 많이 포함하고 있어서 F1과 F2 주파수만 분석 하여 연구에 활용하였다. F1은 혀의 높이와 관련이 있고 F2는 혀의 후설성과 관련되어 있다. 즉, $\mathrm{F} 1$ 값이 낮게 측정될수록 혀 가 높이 있으며, $\mathrm{F} 2$ 값이 낮게 측정될수록 혀의 후설성이 강하 다는 사실을 파악할 수 있다. 또한, Praat 매뉴얼에서는 성인 남 성의 최대 포먼트(maximum formant) 값은 $5,000 \mathrm{~Hz}$ 로 설정하는 것이 가장 적절하다고 설명한다. 따라서 Praat을 활용한 본 연구 의 $\mathrm{F} 1, \mathrm{~F} 2$ 값 검출 과정에서 최고 포먼트 값을 $5,000 \mathrm{~Hz}$ 로 설정 해놓고 측정을 진행하였다. 발화된 모음의 발음 음향 공간 (acoustic space)을 시각적으로 확인하기 위해 도출된 F1 주파수 값과 F2 주파수 값이 서로 만나는 지점을 점으로 찍어 모음 포 먼트 구역으로 나타내었다.

\section{3. 결과 분석 및 논의}

본 연구에서 활용한 K-SEC 코퍼스의 피실험자들 녹음 자료 를 측정한 결과, 개별적인 피실험자들의 포먼트 주파수 값이 차 이를 보이지만 본 연구에서는 각 지역 화자의 일반적인 경향을 파악하기 위해 전체 평균값을 기준으로 분석을 진행하였다.

\section{1. $\mathrm{F} 1, \mathrm{~F} 2$ 측정}

표 1 은 7 개의 한국어 단모음 /이, 애, 으, 어, 아, 우, 오/를 발화 한 서울과 경상 지역 방언 화자의 포먼트 주파수 F1, F2의 평균 값을 도출한 결과를 보여주고 있다. 표준어 화자 7명과 경상 지 역 방언 화자 7명의 피실험자가 발화한 음성 코퍼스 자료를 한 국어 모음 포먼트 주파수를 합산하고 나눈 평균치를 기록하였 다. 표 2는 10 개의 영어 단모음 $/ \mathrm{i}, \mathrm{I}, \varepsilon, \mathfrak{x}, \Lambda, \partial, \mathrm{a}, \mathrm{u}, \mathrm{v}, \mathrm{\partial} /$ 을 발화한 서울과 경상 지역 방언 화자의 포먼트 주파수 $\mathrm{F} 1, \mathrm{~F} 2$ 를 측정한 결과를 보여주고 있다. 두 지역 화자들의 영어 모음 포먼트 주 파수를 측정한 후, 각각 합산하고 나누어 평균치를 기록하였다. 본 연구에서 참고한 미국 영어 모음의 포먼트 주파수 값은 Hillenbrand et al.(1995)에서 측정한 미국 영어 모음의 포먼트 주 파수 값을 나타내고 있다. 해당 연구의 피실험자들 중 $87 \%$ 에 달 하는 대다수는 미국 중북부에 위치한 미시간주에서 성장하였 다. 미국 영어 발음을 구사하는 원어민 화자의 영어 모음 포먼 트 주파수와 한국인 화자의 영어 모음 포먼트 값을 비교해봄으 로써 한국인 화자가 영어 모음을 발화할 때 보이는 일반적인 특 징과 지역 방언이 영어 모음 발음에 미치는 영향을 구분하여 살 펴볼 수 있다.

\subsection{1. 원어민 화자의 영어 모음 발음 비교}

그림 1은 표 1-3의 수치를 포먼트 차트상으로 나타낸 것이다.

표 1. 표준어와 경상도 지역 방언 화자의 한국어 모음 포먼트 주파수 평균값 $(\mathrm{Hz})$

Table 1. Average formant values of Korean vowels spoken by standard Korean and Gyeongsang regional dialect speakers

\begin{tabular}{|c|c|c|c|c|c|c|c|c|c|c|c|c|}
\hline \multirow{2}{*}{\multicolumn{2}{|c|}{ 피실험자 }} & \multirow{3}{*}{$\begin{array}{c}\text { 포먼트 } \\
\text { F1 }\end{array}$} & \multicolumn{10}{|c|}{ 영어 모음 } \\
\hline & & & /i/ & /I/ & $\mid \varepsilon /$ & /æ/ & $/ 2 /$ & $|\Lambda|$ & $/ \mathrm{a} /$ & $/ 2 /$ & $/ \mathrm{u} /$ & $/ \mho /$ \\
\hline \multirow{4}{*}{ 지역별 } & \multirow{2}{*}{ 표준어 } & & 384 & 362 & 568 & 567 & 541 & 553 & 725 & 485 & 459 & 432 \\
\hline & & F2 & 2,134 & 2,057 & 1,588 & 1,749 & 1,008 & 1,164 & 1,282 & 909 & 1,147 & 1,108 \\
\hline & \multirow{2}{*}{ 경상 } & $\mathrm{F} 1$ & 363 & 385 & 568 & 556 & 463 & 577 & 712 & 463 & 439 & 420 \\
\hline & & $\mathrm{F} 2$ & 2,080 & 2,106 & 1,689 & 1,778 & 925 & 1,107 & 1,212 & 857 & 993 & 979 \\
\hline
\end{tabular}

표 2. 표준어와 경상도 지역 방언 화자의 영어 모음 포먼트 주파수 평균값 $(\mathrm{Hz})$

Table 2. Average formant values of English vowels spoken by standard Korean and Gyeongsang regional dialect speakers

\begin{tabular}{|c|c|c|c|c|c|c|c|c|c|c|c|}
\hline \multicolumn{2}{|c|}{ 영어모음 } & /i/ & $/ \mathrm{I} /$ & $\mid \varepsilon /$ & $/ æ /$ & $\mid \Lambda /$ & $10 /$ & /a/ & $/ 2 /$ & $/ \mathrm{J} /$ & $/ \mathrm{u} /$ \\
\hline \multirow{2}{*}{ 미국인 } & F1 & 342 & 427 & 580 & 588 & 623 & 474 & 768 & 652 & 469 & 378 \\
\hline & $\mathrm{F} 2$ & 2,322 & 2,034 & 1,799 & 1,952 & 1,200 & 1,379 & 1,333 & 997 & 1,122 & 997 \\
\hline
\end{tabular}




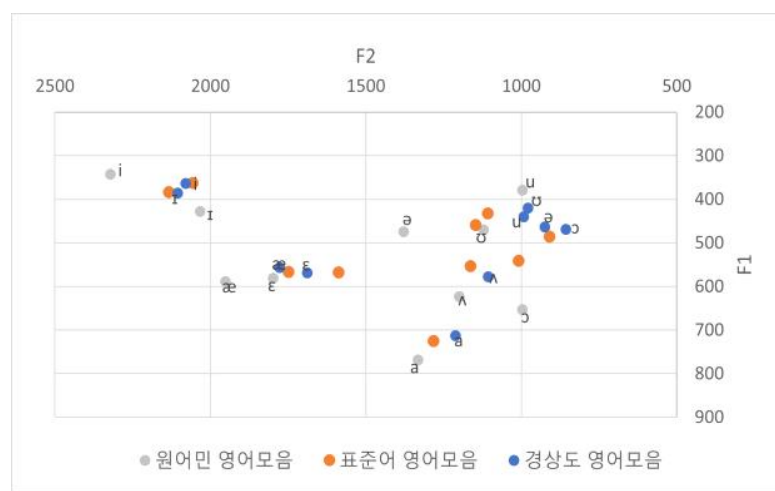

그림 1. 원어민, 표준어, 경상 방언 화자의 영어 모음 포먼트 구역

Figure 1. Articulatory regions of English vowels by native, standard Korean and Gyeongsang regional dialect speakers

한국인 표준어와 경상 방언 화자의 영어 모음 포먼트 구역을 미국 영어 원어민이 발화한 모음의 포먼트 주파수 평균값과 비 교해볼 수 있다. 그 결과 원어민 화자의 영어 모음 조음 구역이 한국인 화자보다 넓다는 것을 알 수 있다. 즉, 10 모음의 조음 구 역이 한국인 화자에 비교했을 때, 더 넓은 구역에 걸쳐 분포해 있다는 사실을 확인할 수 있다. 또한, 한국인 화자는 긴장 모음 과 이완 모음이 유사한 조음 구역에서 발음되었지만, 원어민 화 자는 긴장 모음과 이완 모음의 구분이 비교적 뚜렷하게 나타났 다. 그뿐만 아니라, 한국인 화자들에게서 비슷한 조음 구역에서

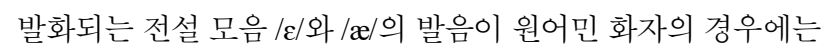
명확하게 구분되어 조음 되었음을 알 수 있었다.

\subsection{2. 표준어와 경상 방언 화자의 한국어 모음 발음}

표 1 에 제시된 표준어와 경상 방언 화자의 한국어 모음 포먼 트 평균 수치를 통해 두 지역 방언 화자의 모음 발음 특징을 비 교해볼 수 있다. 그리고 표에 나타난 주파수 평균값을 모음 포 먼트 구역으로 시각화하여 그림 2와 같이 나타낼 수 있다.

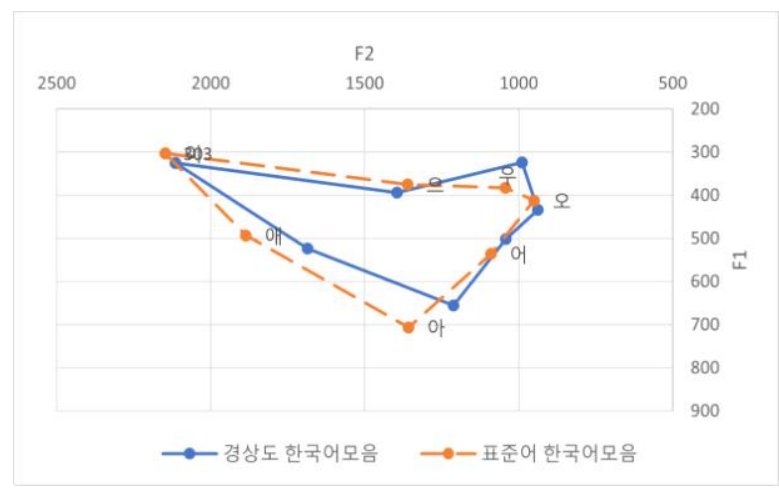

그림 2. 표준어와 경상 방언 화자의 한국어 모음 포먼트 구역

Figure 2. Articulatory regions of Korean vowels by standard Korean and Gyeongsang regional dialect speakers

그림 2 를 통해 확인할 수 있는 음향 공간상의 조음 위치에 관 한 특징은 경상도 방언 화자가 한국어 모음을 발화할 때 표준어
화자보다 후설 쪽에서 발음한다는 점이다. /이/ 모음을 제외한 다른 6 모음에서 모두 후설성이 강하게 나타난다. 이러한 결과 는 Myung \& Lee(2014)에서 확인되었다. 또한, 후설 고모음/우/ 발음에서 경상도 지역방언 화자가 표준어 화자보다 고모음으 로 발음한다는 것을 알 수 있다. 이는 Sohn \& Ahn(2009)의 견해 와도 일치하는 결과이다. 뿐만 아니라, /우/ 발음 시 혀의 높이에 서도 차이를 보인다. 경상도 지역 방언 화자가 표준어 화자보다 /우/ 발음 시에 혀를 높이 조음한다는 사실을 확인할 수 있다.

\section{2. 표준어와 경상 방언 화자의 영어 모음 발음}

표 2는 표준어와 경상도 지역 방언 화자의 영어 모음 포먼트 주파수 평균값을 수치로 나타내고 있다. 그림 3은 표 2의 수치 를 모음 포먼트 구역으로 시각화하여 나타내고 있으며, 이를 통 해 음향 공간상 조음 위치를 확인하고 지역 방언의 영어 모음 발음 특징을 확인해보고자 한다.

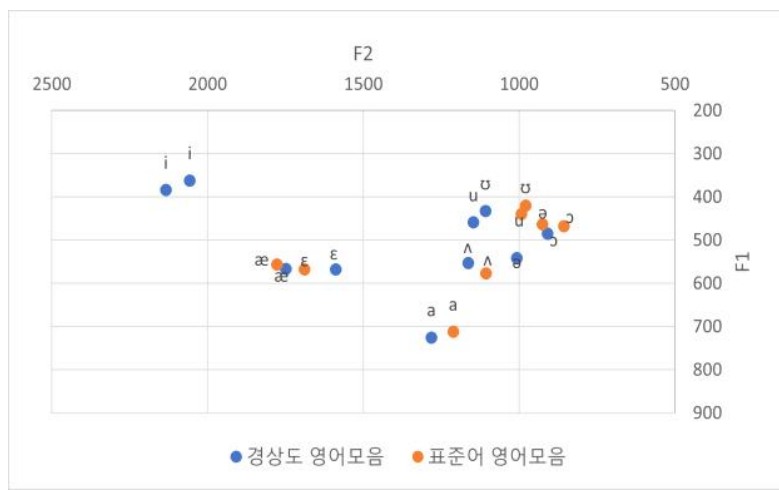

그림 3. 표준어와 경상 방언 화자의 영어 모음 포먼트 구역

Figure 3. Articulatory regions of English vowels by standard Korean and Gyeongsang regional dialect speakers

그림 3 는 표 2 의 경상도와 서울 방언 화자의 영어 모음 발음 포먼트 주파수 평균 수치를 시각화한 자료이다. 그림 3에서 드 러나는 표준어와 경상 지역 방언 화자의 영어 모음 조음 시 공 통점은 긴장 모음과 이완 모음이 구별되지 않는다는 사실이다. 즉, 긴장 모음인 $/ \mathrm{i} /, / \mathrm{J} /$ 와 이완 모음/I/, / / / 이 유사한 조음 구역에 서 발음된다. 이와 같은 결과는 여러 선행 연구에서 동일하게 나타났다(Han \& Lee, 2002; Hwang, 2001; Hwang \& Moon, 2005; $\mathrm{Koo}, 2001)$. 따라서 영어 모음 발음에서 긴장 모음과 이완 모음 이 구분되지 않는 것은 지역 방언의 영향과 무관하게 한국어 화 자의 일반적인 영어 모음 발음 특징이라고 할 수 있다. 또한, 그 림 3 에서 영어 전설 모음에 해당하는 $/ \mathrm{i}, \mathrm{I}, \varepsilon, \mathfrak{x} /$ 발음을 제외하고 전반적인 모음들을 발음할 때 경상도 지역 방언 화자가 표준어 화자보다 조음 영역이 후설 쪽에 위치한다는 결론을 얻을 수 있 다. 이는 한국어 모음 발음 시에도 동일하게 나타난 현상이므로, 모국어 지역방언 발음이 영어 모음 발음에 영향을 주었다고 할 수 있다. 그리고 경상도 방언에서 구분되지 않는/으/와/어/ 모 음 발음에 대치되는 영어 모음 발음인 / / $/$ 와/a/가 경상도 지역 방언 화자의 경우, 매우 유사한 조음 구역에서 발음되었으나 표 
준어 화자는 $/ \mho /$ 와/ə/가 명확히 다른 조음 구역에서 발음되었음 을 확인할 수 있었다. 이러한 결과는 7 모음을 발음하는 표준어 화자와 달리 /으/와 /어/의 발음을 /어/로 통합하여 발음하는 경 상 지역 방언 화자들의 모음 발음 특징에서 발생한 현상이라고 볼 수 있으며, $\operatorname{Koo(2001)ㅇㅢ~ㅈㅜㅈㅏㅇㄱㅘㄷㅗ~ㅇㅣㄹㅊㅣㅎㅏㄴㄷㅏ.~ㄱㅡㄹㅓㄴㅏ~ㅎㅏㄴㄱㅜㄱㅇㅓ~}$ 모음 발음에서 경상도 지역방언 화자가 표준어 화자보다 현저 히 고모음으로 조음했던 /우/에 대치되는 영어 모음 발음인 /u/, / $/$ 는 경상도 지역 방언 화자가 후설성이 비교적 강하게 조음한 다는 것 외에는 큰 차이를 보이지 않았다.

\section{4. 결론}

본 연구에서는 표준어와 경상 지역 방언 남성 화자의 한국어 모음 발음이 영어 모음 발음에 미치는 영향에 대해 분석하였다. 원어민과 표준어, 경상 방언 화자의 영어 모음 포먼트 구역을 비교함으로써 한국어 지역 방언의 사용이 야기한 영어 모음 발 음의 영향과 한국어 모음 발음의 일반적인 특징이 야기한 영어 모음 발음의 영향을 구분하여 해석할 수 있었다. 분석 결과, 경 상 방언 화자가 표준어 화자보다 한국어 모음/이/를 제외한 나 머지 6 가지 모음인 /에, 으, 어, 아, 오, 우/를 발음할 때 조음 영 역이 비교적 후설쪽에서 조음된다는 결과를 얻었다. 이러한 현 상은 영어 모음을 발음할 때에도 동일하게 나타났다. 경상도 방 언 화자가 전설 모음 $/ \mathrm{i}, \mathrm{I}, \varepsilon, æ /$ 를 제외한 나머지 6 가지 모음인 /o, $\Lambda, \mathrm{a}, \mathrm{o}, \mathrm{u}, \mathrm{v} /$ 를 발음할 때 표준어 화자가 같은 모음을 발음했을 때보다 후설성이 강하게 나타났다. 또한, 7 모음이 발음되는 표 준어와 달리 경상 방언은/으/와/어/가/어/ 발음으로 통합되어 6 모음이 조음 되는데, /으/와/어/ 각각에 대치되는 영어 모음 발 음/ひ/와/2/가 표준어 화자와는 다르게 경상 방언 화자에게서 매 우 근접한 조음 구역에서 발화된다는 것을 확인할 수 있었다. 그러나 경상 방언 화자가 후설 고모음/우/를 발음할 때, 서울 방 언 화자보다 높은 위치에서 조음 되었는데 대치되는 영어 모음 / $/$ 를 발음할 때에는 동일한 현상이 나타나지 않았다. 또한, 원 어민 화자의 모음 포먼트 구역과 표준어, 경상 방언 화자 각각 의 포먼트 구역의 비교를 통해 표준어와 경상 방언 화자 모두에 게 영어의 긴장 모음과 이완 모음이 구분되지 않는다는 것을 확 인할 수 있었다. 이와 같은 현상은 표준어와 경상 방언 화자에 게서 공통으로 드러난 특성이므로 지역 방언의 차이에서 비롯 되었다고 보기 힘들며, 오히려 긴장 모음과 이완 모음을 구분 짓지 않는 한국어 모음 체계를 학습해온 한국인 모음 발음의 일 반적인 특징인 것으로 볼 수 있다. 그리고 표준어, 경상 방언 화 자는 원어민 화자보다 조음 구역이 좁아 긴장 모음과 이완 모음 의 구별이 모호하다. 즉, 한국인은 전설 모음 $/ \varepsilon, æ /$ 의 구분이 불 명확한 반면에 원어민은/ $/$, $/$ 의 발음이 비교적 명확하다는 점 을 알 수 있었다.

본 연구의 결과는 추후에 지역방언 화자의 발음 교육에 이용 될 수 있을 것이다. 한국인의 일반적인 발음 특징을 토대로 교 육을 진행하는 것에서 한 발자국 더 나아가 화자별 모음 구역을 고려하고 교육에 활용함으로써 발음 교육의 효과를 높일 수 있
을 것이다.

\section{References}

Boersma, P., \& Weenink, D. (2021). Praat: Doing phonetics by computer [computer program]. Retrieved from http://www. praat.org

Han, Y., \& Lee, S. (2002). An experimental phonetic study on English vowel production by native speakers of Korean. Phonetics, 44, 15-32.

Hillenbrand, J., Getty, L. A., Clark, M. J., \& Wheeler, K. (1995). Acoustic characteristics of American English vowels. The Journal of the Acoustical Society of America, 97(5), 30993111.

Hwang, Y. S. (2001). A comparative analysis on English vowels of Korean students by formant frequencies. Korean Society of Speech Sciences, 8(4), 221-228.

Hwang, H., \& Moon, S. J. (2005). An acoustic comparative study of Korean /에, 애/ and English / $\varepsilon$, \ae/ pronounced by Korean young male speakers. Malsori, 56(4), 29-47.

Koo, H. (2001). An acoustic study of the pronunciation of English vowels uttered by Korean regional dialect speakers. Speech Sciences, 8(4), 193-206.

Ladefoged, P., \& Johnson, K. (2011). A course in phonetics (6th ed.). Boston, MA: Wadsworth/Cengage Learning.

Lee, K. Y., \& Cho, M. H. (2013). Production of English vowels by Korean learners. The Korea Contents Association, 13(9), 495-503.

Lee, S., Kang, J., Shin, D. J., \& Nam, H. (2019). The effect of dialect experience and talker variation on Korean EFL listeners' English vowel identification. Studies in Foreign Langauge Education, 33(4), 1-27.

Myung, Y., \& Lee, D. (2014). A study on south Kyungsang Korean native speakers' production of English high vowels. Language Sciences, 21(1), 21-40.

Park, D., Shinsook, L., \& Cho, M. H. (2010). Interference of L1 phonological processes in English learning. English Language and Linguistics, 16(3), 187-215.

Park, J. (2009). An acoustic study of English single vowels by Korean adult learners (Masters thesis). Kyonggji University, Suwon, Korea.

Seo, M. S. (2011). An acoustic analysis of Korean and English vowels produced by Korean speakers: Focus on Taegu and Cheju dialect speakers (Master's thesis). Kyungpook National University, Daegu, Korea.

Rhee, S. C., Lee, S. H., Kang, S. K., \& Lee, Y. J. (2003). Design and construction of Korean-Spoken English Corpus (K-SEC). Malsori, 46, 159-174. 
Sohn, H. S., \& Ahn, M. (2009). An experimental study on the vowel space of Korean and English spoken by female speakers of Daegu dialect. The Journal of Linguistic Science, 49, 117-140.

- 장수연 (Soo-Yeon Jang) 교신저자 연세대학교 영어영문학과 석사과정

서울시 서대문구 연세로 50

Tel: 02-1599-1885

Email: sooyun1300@naver.com

관심분야: 음성학, 음운론 


\title{
표준어와 경상 지역 방언의 한국어 모음 발음에 따른 영어 모음 발음의 영향에 대한 연구
}

\author{
장 수 연
}

연세대학교 영어영문학과

\begin{abstract}
국문초록
본 논문의 목적은 한국어 표준어와 경상 지역 방언의 한국어 모음 발음의 영어 모음 발음에 대한 영향을 연구하는 데 있다. 데이터 자료는 한국인의 영어 발음 음성 코퍼스(Korean-Spoken English Corpus, K-SEC)를 활용하였다. 이 중 일곱 개의 한국어 단모음이 포함된 단어와 열 개의 영어 단모음이 포함된 단어가 선정되어 분석되었다. 선정된 자료는 외국 거주 경험이 없는 성인 남성 표준어 화자와 경상 지역 방언 화자에 의해 발화되었다. 녹음된 코퍼스 자 료의 포먼트 주파수는 음성 분석 프로그램인 Praat에서 제공하는 스펙트로그램을 통해 측정되었다. 녹음된 자료들 은 포먼트 구역 그래프로 나타내어 분석되었다. 결과에 의하면, 한국어와 영어 모음의 발화에서 경상 지역 방언 화 자가 강한 후설성을 보인 반면에 표준어 화자는 비교적 전설성이 강하게 나타났다. 또한, 표준어와 경상 지역 방언 의 한국어 모음 발음 차이 $(/$ 으/, / 어 $/)$ 는 대치되는 영어 모음 발음 $(/ \mathrm{J} / / \mathrm{v} /)$ 의 조음 방식에 영향을 미쳤다. 지역 방언의 사용과 무관한 한국인의 일반적인 모음 발음 특징은 영어 원어민 화자보다 조음 구역이 좁다는 것이다. 이에 한국 인은 전반적으로 긴장 모음과 이완 모음을 구별하는 데 어려움이 있지만, 영어 원어민 화자는 모음 조음에 명확한 구분이 있다.
\end{abstract}

핵심어: 포먼트 주파수, 한국인의 영어 발음, 한국어 모음, 지역 방언

\section{참고문헌}

구희산(2001). 지역방언 화자에 따른 영어 모음의 발음 연구. 음성과학, 8(4), 193-206.

명윤미, 이동명(2014). 경남방언 남.여 화자의 영어 고모음 발 화에관한 연구. 언어과학, 21(1), 21-40.

박재일(2009). 한국인 성인 화자의 영어 단모음 발화에 관한 음 향음성학적 분석. 경기대학교 석사학위논문.

서미석(2011). 한국어 화자의 한국어와 영어 모음 발화에 나타 난 음향음성학적 특성: 대구방언과 제주방언 화자를 대상 으로 경북대학교 석사학위논문.

손형숙, 안미애(2009). 한국어와 영어의 모음 발음영역에 대한 실험음성학적 연구: 대구 지역 여성화자를 대상으로. 언어 과학연구, 49, 117-140.

이계윤, 초미희(2013). 한국인 학습자의 영어 모음 발화 연구. 한국콘텐츠학회논문지, 13(9), 495-503.

이석재, 이숙향, 강석근, 이용주(2003). 한국인의 영어 음성 코 퍼스 설꼐 및 구축. 말소리, 46, 159-174.

이신숙, 강재구, 신동진, 남호성(2019). 방언 차이와 화자 변이 가 한국인 $\mathrm{EFL}$ 청자의 영어 모음 인지에 미치는 영향. 외국 어교육연구, 33(4), 1-27.
한양구, 이숙향(2002). 한국어 모국어 화자의 영어 모음 발성 에 관한 실험음성학적 연구. 말소리, 44, 15-32.

황영순(2001). 포먼트에 의한 영어모음 비교 분석. 음성과학, 8(4), 221-228.

황혜정, 문승재(2005). 한국인이 발음한 한국어 /에, 애/와 영어 $/ \varepsilon, æ /$ 모음. 말소리, 56(4), 29-48. 